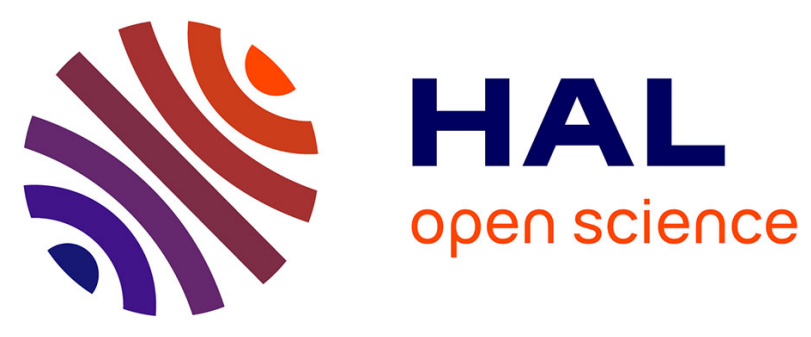

\title{
MEMS high temperature gradient sensor for skin-friction measurements in highly turbulent flows
}

Cécile Ghouila-Houri, Abdelkrim Talbi, Romain Viard, Quentin Gallas, Eric Garnier, Pascal Molton, Jérôme Delva, Alain Merlen, Philippe Pernod

\section{To cite this version:}

Cécile Ghouila-Houri, Abdelkrim Talbi, Romain Viard, Quentin Gallas, Eric Garnier, et al.. MEMS high temperature gradient sensor for skin-friction measurements in highly turbulent flows. 2019 IEEE SENSORS, Oct 2019, Montreal, Canada. 10.1109/SENSORS43011.2019.8956802 . hal-02904476

\section{HAL Id: hal-02904476 \\ https://hal.science/hal-02904476}

Submitted on 22 Jul 2020

HAL is a multi-disciplinary open access archive for the deposit and dissemination of scientific research documents, whether they are published or not. The documents may come from teaching and research institutions in France or abroad, or from public or private research centers.
L'archive ouverte pluridisciplinaire HAL, est destinée au dépôt et à la diffusion de documents scientifiques de niveau recherche, publiés ou non, émanant des établissements d'enseignement et de recherche français ou étrangers, des laboratoires publics ou privés. 


\title{
MEMS high temperature gradient sensor for skin- friction measurements in highly turbulent flows
}

\author{
Cecile Ghouila-Houri ${ }^{1}$, Abdelkrim Talbi ${ }^{1}$, Romain Viard ${ }^{2}$, Quentin Gallas ${ }^{3}$, Eric Garnier ${ }^{4}$, Pascal Molton ${ }^{4}$, Jérôme \\ Delva $^{3}$, Alain Merlen ${ }^{1}$, Philippe Pernod ${ }^{1}$ \\ ${ }^{1}$ Univ. Lille, CNRS, Centrale Lille, ISEN, Univ. Valenciennes, UMR 8520 - IEMN, LIA LICS, F-59000 Lille, France \\ ${ }^{2}$ Fluiditech, F-68200 Mulhouse, France \\ ${ }^{3}$ ONERA The French Aerospace Lab, F-59000 Lille, France \\ ${ }^{4}$ ONERA The French Aerospace Lab, F-92190 Meudon, France
}

\begin{abstract}
This paper presents and discusses the results obtained with a MEMS high temperature gradient sensor for time-averaged and fluctuating skin-friction measurements in highly turbulent flows. Designed as a robust wall-mounted suspended hot-wire structure, the micro-sensor showed a high temperature variation for low power consumption. Successfully implemented into two air wind tunnels, the sensor was tested for velocities going up to $270 \mathrm{~m} / \mathrm{s}$, mean velocity of airliner cruise flights, and corresponding to a shear stress of $150 \mathrm{~Pa}$. The microsensor thereby demonstrated its value for measuring turbulence in aerodynamic applications, particularly in aeronautics.
\end{abstract}

Keywords-Thermal sensor, MEMS, turbulence measurements

\section{INTRODUCTION}

Turbulence has been a complex field of study for fluid mechanics since its introduction in 1933 by O. Reynolds. It is indeed characterized by a disorderly behaviour with vortices whose size, location and orientation constantly vary. In fact, understanding, predicting and controlling turbulence are the three major goals of research in this domain. The consequences are crucial: predicting the behaviour of turbulent flows in order to control and manipulate them would, in many fields of application, save energy, improve systems performances and protect the environment [1]. The most obvious example is the one of transport industry, which is confronted to the problem of aerodynamic drag on vehicles. Controlling turbulence for this application means manipulating the laminar-turbulent transition of the flow around the vehicle, controlling the phenomenon of separation of the boundary layer or reducing the noise pollution... in order to reduce power and fuel consumptions and limit $\mathrm{CO}_{2}$ and $\mathrm{NO}_{\mathrm{x}}$ emissions.

However, turbulence is an unresolved problem in classical physics and does not present a simple solution. Numerical simulations make it possible to find solutions in the case of simplified geometries and low Reynolds number flows. Still, to target industrial applications, it is necessary to work in flows with high Reynolds numbers and with complex geometries. It is then impossible to predict the behaviour of turbulence in these configurations without relying on empirical data [2]. In other words, numerical calculations need modelling, analysis and especially experimentation. Nevertheless, working in turbulent high Reynolds numbers generates very short spatial and temporal scales: spatial scales whose order of $100 \mu \mathrm{m}$ or less and time scales require a bandwidth of at least $10 \mathrm{kHz}$ [3]. Experiments thus require small, fast, implementable sensors in various configurations and models, and allowing non-intrusive measurements of the flow. More precisely, the aerodynamicists require sensors allowing the measurement of skin-friction also called wall shear stress [4]. This parameter that corresponds to the tangential viscous force of the fluid at the wall is indeed essential in turbulence equations.

Micro Electro Mechanical Systems (MEMS) are devices whose characteristic lengths are submillimetre. Therefore, they can reach the required spatial scales in fluids mechanics. In addition, downscaling leads to an increase of the sensitivity to small and fast fluctuations. Consequently, MEMS sensors dedicated to fluid mechanics and aerodynamics have been developed, particularly for the measurement of turbulence and reactive flow control. Thermal wall shear stress sensors have then been developed, exploiting the heat transfer by forced convection between an electrically heated wire and the flow. The manufactured sensors were mainly based on hot-film design, which allows robustness but suffers from conduction in the film [5]-[9]. Another design is the one of wall mounted hot-wire sensors ([10], [11]). However, these structures are intrusive in the flow and they are fragile and therefore not suitable for high-speed flows.

In this paper, we present a thermal based MEMS sensor designed for high sensitive skin-friction measurements and tested in highly turbulent flows whose velocity goes up to $270 \mathrm{~m} / \mathrm{s}$. The microstructure of the sensor combines free standing hot-wire, avoiding conduction in the substrate, and mechanical robustness. This design enables a high temperature gradient localized in $3 \mu \mathrm{m} \times 1 \mathrm{~mm}$ area. The micro-sensor was tested in low Mach number flows, that is to say in flow whose velocity goes up to $40 \mathrm{~m} / \mathrm{s}$, as well as in high Mach number flows whose velocity ranges from $180 \mathrm{~m} / \mathrm{s}$ to $270 \mathrm{~m} / \mathrm{s}$.

\section{HIGH TEMPERATURE GRADIENT MICRO-SENSOR}

\section{A. Sensor microstructure design}

The MEMS sensor is based on a patented thermal microstructure [12] characterized by both a high temperature gradient and a high robustness. It is composed of a suspended 


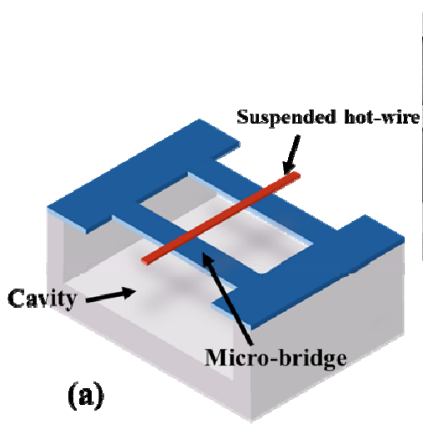

Fig. 1.(a) Schematic of the Microscopy image of the mid zooming on the multilayer $\mathrm{w}$

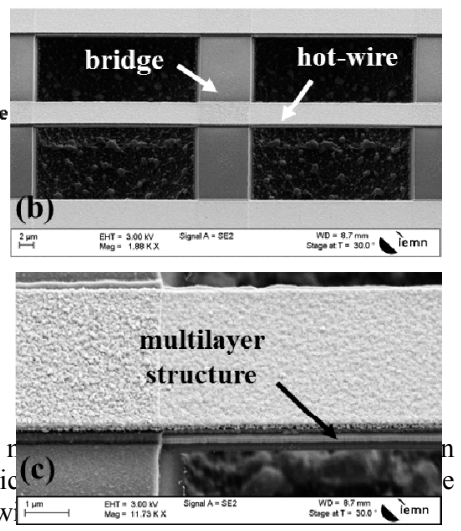

3 - $\mu \mathrm{m}$-wide by $1-\mathrm{mm}$-long micro-hot-wire separated from the substrate by a $20-\mu \mathrm{m}$-deep cavity and mechanically supported along its length by periodic micro-bridges as shown in Fig. 1 (a) and (b). The hot-wire structure is multilayered (Fig. 1 (c)): the heater gold layer is on top of the wire, and then comes an insulator $\mathrm{SiO} 2$ layer (in black) and the $\mathrm{Ni} / \mathrm{Pt}$ alloy measurement wire. The final bottom $\mathrm{SiO} 2$ layer for robustness. As detailed in [13], [14], measurement and heating have been uncoupled in this microstructure, unlike conventional hot-film and hot-wire sensors. This particularity improves the performances of the sensors by uncoupling the choice of materials: gold is very stable against oxidation and temperature and is therefore perfect for heating whereas $\mathrm{Ni} / \mathrm{Pt}$ performs high sensitivity to temperature for measurements. The fabrication of the devices was realized in the cleanroom at IEMN, using CMOS-compatible MEMS techniques.

\section{B. Electro-thermal characterizations}

We characterized the thermal properties of the microstructure to evaluate the performances and sensitivity of the micro-sensor. The measurement of the temperature coefficient of resistance, realized using a hot plate, gave about $0.24 \% /{ }^{\circ} \mathrm{C}$ [14]. We used a thermal infrared camera for evaluating the thermal profile as shown in Fig. 2. The microstructure is heated at $40^{\circ} \mathrm{C}$ for realizing the thermal image. We measured a high temperature gradient with a variation of temperature of $70^{\circ} \mathrm{C}$ for only $7 \mathrm{~mW}$ of heating power. This result also shows that the heating is confined in the $3-\mu \mathrm{m}$-wide wire: the thermal insulation from the substrate is successfully achieved.

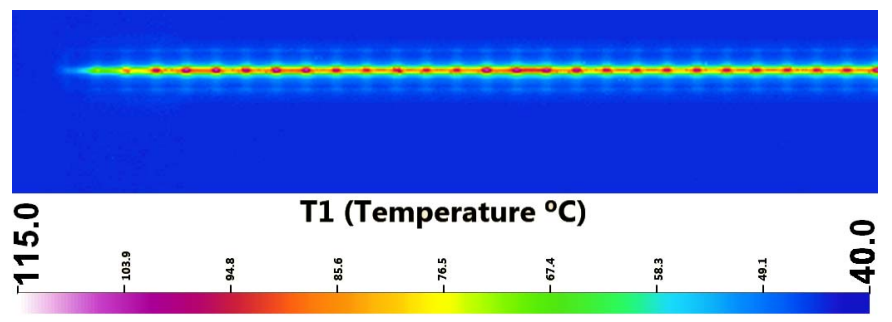

Fig. 2. Thermal imaging of the micro-sensor heated with $7 \mathrm{~mW}$ and achieving $70^{\circ} \mathrm{C}$ of temeprature variation.

\section{MEASUREMENTS IN TURBULENT FLOWS}

The micro-sensor is devoted to wall shear stress measurements in turbulent flows. We tested it in two different air wind tunnels addressing two ranges of wall shear stress. We characterized its time-average response as well as its dynamic response to fluctuations.

\section{A. Implementation in wind tunnels}

Firstly, we tested the micro-sensor in a wind tunnel in ONERA Lille, presented a low velocity range going up to $40 \mathrm{~m} / \mathrm{s}$. In terms of Mach number, which is the ratio of the airflow velocity to the velocity of sound in air, it corresponds to a maximum Mach number of 0.1 . Previous works presented the wind tunnel geometry and the way we evaluated the corresponding wall shear stress in the test section ([14], [15]). The range of skin-friction considered here is 0 to $2.5 \mathrm{~Pa}$.

The second set of measurements took place in the $\mathrm{S} 8 \mathrm{Ch}$ wind tunnel in ONERA Meudon (Fig. 3). The mainstream flow velocity in this facility ranges from $180 \mathrm{~m} / \mathrm{s}$ to $270 \mathrm{~m} / \mathrm{s}$ corresponding to a Mach number ranging from 0.5 to 0.79 . The measurement of the wall velocity gave an estimation of the wall shear stress by (1).

$$
\tau=u_{w a l l}^{2} \times \rho
$$

where $\tau$ is the wall shear stress, $u_{\text {wall }}$ the wall velocity and $\rho$ the density.

In both cases, the micro-sensor was implemented on a flat plate designed for wall shear stress measurements in an established boundary layer.

\section{B. Results and discussions}

The MEMS thermal sensor works in constant temperature mode where electronics regulate the heating current to maintain the wire temperature constant. Therefore, the variation of heating current is the measured variable as a function of either the mainstream velocity or the skin-friction.

Fig. 4 presents the time-averaged measurements and the estimated wall shear stress as function of the mainstream velocity.

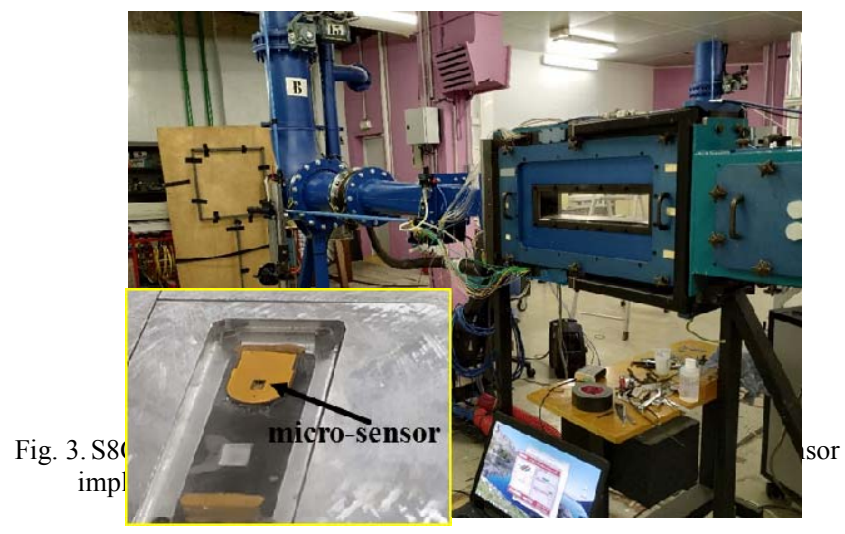




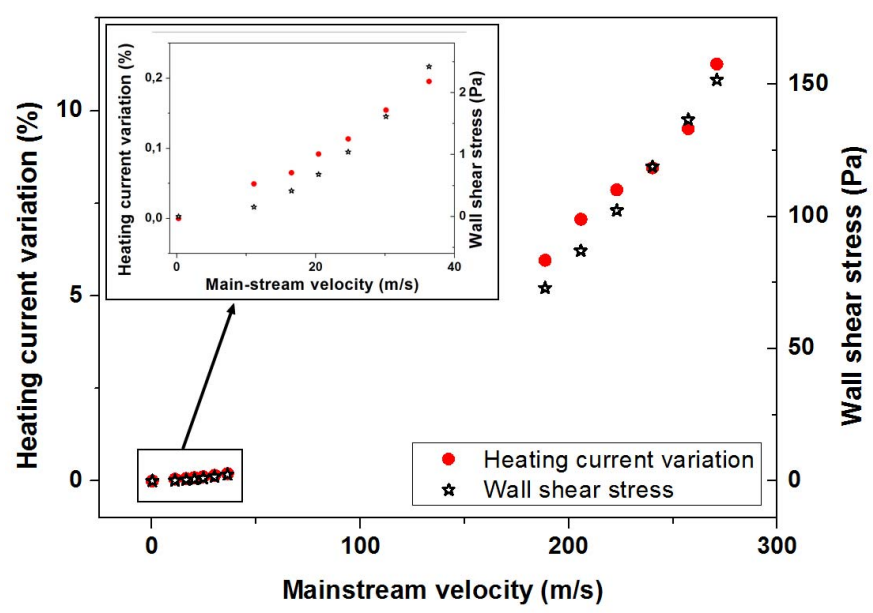

Fig. 4. Time-average response of the micro-sensor as function of the main-stream flow velocity and with the correcponsing wall shear stress measured. Inset: zoom on the measuremet realized for velocities inferior to $40 \mathrm{~m} / \mathrm{s}$

The sensor presents a high sensitivity to wall shear stress with more than $10 \%$ variation for a corresponding shear stress of $150 \mathrm{~Pa}$ (mainstream velocity of $270 \mathrm{~m} / \mathrm{s}$ and corresponding Mach number of 0.79). These results demonstrate the robustness and the usefulness of the micro-sensor for flow measurements in high-speed flows, compatible with velocities on airliners (Mach number ranging $0.7-0.8$ ).

We also evaluated the sensor response to velocity fluctuations by measuring the power spectral density. More precisely, the frequency weighted power spectral density corresponds to the turbulent kinetic energy of the flow [16]. As shown in Fig. 5, it is characterized by a hump shape. The interval of frequency centered in the hump is characteristic of the turbulent eddies that transport energy in the flow. For a mainstream velocity of $36 \mathrm{~m} / \mathrm{s}$, which corresponds to a Mach number close to 0.1 , the hump is reach for $700 \mathrm{~Hz}$. For a Mach number of $0.79(270 \mathrm{~m} / \mathrm{s})$, the hump is reached for $5.3 \mathrm{kHz}$.

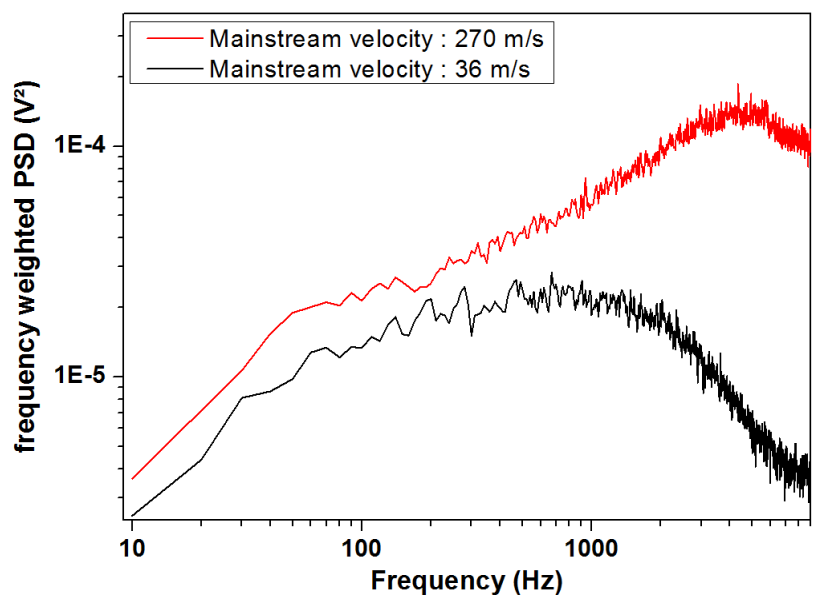

Fig. 5. Frequency-weighted power spectral density (PSD) measured for $36 \mathrm{~m} / \mathrm{s}$ and $270 \mathrm{~m} / \mathrm{s}$ mainstream velocities.
The factor between the two Mach number is aso obtained between the two hump frequencies. Ongoing work on the electronics aims at widening the bandwidth of the sensor to capture the complete high-speed turbulent spectrum.

Overall, the wind tunnel experiments demonstrated that the high temperature gradient micro-sensor is suitable for turbulence measurements in high-speed flows for aerodynamic aplications.

\section{CONCLUSION}

In this paper, we discussed the results obtained with a high temperature gradient MEMS sensor for airflow measurements in highly turbulent flows. We presented the original design of the suspended micro-wire thermal structure that demonstrated high sensitivity, with a high variation of temperature for low power, and high robustness in wind tunnel experiments. Experiments were performed in low-speed and high-speed subsonic wind tunnels.

The results demonstrated the ability of the MEMS sensor to perform time-averaged and fluctuating wall shear stress measurements up to $150 \mathrm{~Pa}$, corresponding to Mach-0.8turbulent flows with mainstream velocity of $270 \mathrm{~m} / \mathrm{s}$, mean velocity of cruise airliner flights. The presented results thereby show the value of the MEMS sensor for aerodynamic applications.

Further work will focus on increasing the sensor sensitivity to small spatial and temporal turbulent scales for testing its response in transonic and supersonic flows.

\section{ACKNOWLEDGMENT}

This work is funded by the French National Research Agency (ANR) in the framework of the ANR ASTRID "CAMELOTT" project. It is supported by the regional platform CONTRAERO in the framework of the CPER ELSAT 2020 project. The authors also thank RENATECH, the French national nanofabrication network, and FEDER.

\section{REFERENCES}

[1] Gad-el-Hak, "Flow Control: The Future," Journal of Aircraft, vol. 38, no. 3, pp. 402-418, 2001.

[2] L. Löfdahl and M. Gad-el-Hak, "MEMS applications in turbulence and flow control," Progress in Aerospace Sciences, vol. 35, no. 2, pp. 101-203, Feb. 1999.

[3] N. Kasagi, Y. Suzuki, and K. Fukagata, "Microelectromechanical Systems-Based Feedback Control of Turbulence for Skin Friction Reduction," Annual Review of Fluid Mechanics, vol. 41, no. 1, pp. 231-251, 2009.

[4] J. W. Naughton and M. Sheplak, "Modern developments in shearstress measurement," Progress in Aerospace Sciences, vol. 38, no. 6, pp. 515-570, Aug. 2002.

[5] M. Sheplak, V. Chandrasekaran, A. Cain, T. Nishida, and L. N. Cattafesta III, "Characterization of a silicon-micromachined thermal shear-stress sensor," AIAA Journal, vol. 40, no. 6, pp. 1099-1104, 2002.

[6] Q. Lin, Y. Xu, F. Jiang, Y.-C. Tai, and C.-M. Ho, "A parametrized three-dimensional model for MEMS thermal shear-stress sensors," Journal of Microelectromechanical Systems, vol. 14, no. 3, pp. 625633, Jun. 2005.

[7] H.-B. Liu, N. Lin, S.-S. Pan, J. Miao, and L. K. Norford, "High Sensitivity, Miniature, Full 2-D Anemometer Based on MEMS Hot- 
Film Sensors," IEEE Sensors Journal, vol. 13, no. 5, pp. 1914-1920, May 2013.

[8] I. Haneef et al., "A tungsten based SOI CMOS MEMS wall shear stress sensor," in IEEE SENSORS 2014 Proceedings, 2014, pp. 14751478.

[9] T. S. Leu, J. M. Yu, J. J. Miau, and S. J. Chen, "MEMS flexible thermal flow sensors for measurement of unsteady flow above a pitching wind turbine blade," Experimental Thermal and Fluid Science, vol. 77, pp. 167-178, Oct. 2016.

[10] L. Löfdahl, V. Chernoray, S. Haasl, G. Stemme, and M. Sen, "Characteristics of a hot-wire microsensor for time-dependent wall shear stress measurements," Experiments in Fluids, vol. 35, no. 3, pp. 240-251, 2003.

[11] U. Buder, A. Berns, E. Obermeier, R. Petz, and W. Nitsche, "AeroMEMS wall hot-wire anemometer on polyimide foil for measurement of high frequency fluctuations," in Sensors, 2005 IEEE, 2005, pp. 4-pp.
[12] C. Ghouila-Houri et al., "Robust thermal microstructure for designing flow sensors and pressure sensors," in 2017 IEEE SENSORS, 2017, pp. 1-3.

[13] C. Ghouila-Houri et al., "High temperature gradient micro-sensor for wall shear stress and flow direction measurements," Appl. Phys. Lett., vol. 109 , no. 24, p. 241905 , Dec. 2016.

[14] C. Ghouila-Houri et al., "High temperature gradient calorimetric wall shear stress micro-sensor for flow separation detection," Sensors and Actuators A: Physical, vol. 266, pp. 232-241, Oct. 2017.

[15] C. Ghouila-Houri et al., "Unsteady flows measurements using a calorimetric wall shear stress micro-sensor," Exp Fluids, vol. 60, no. 4, p. 67, Mar. 2019.

[16] R. Mathis, I. Marusic, S. I. Chernyshenko, and N. Hutchins, "Estimating wall-shear-stress fluctuations given an outer region input,” Journal of Fluid Mechanics, vol. 715, pp. 163-180, Jan. 2013. 